\title{
CMEARTICLE
}

\section{Diabetic kidney disease in primary care}

Jie Ming Nigel Fong $^{1, *}$, MBBS(Hons), Li Ping Marianne Tsang $^{2, *}$, MBBS, MRCP, Jia Liang $\underline{K w e k}^{3}$, MRCP, FAMS, Weiwen $\underline{\mathrm{GuO}}^{4}$, MBBS, MRCP

Mdm Chee, a 55-year-old homemaker, visited your clinic for a routine follow-up for her chronic conditions. She shared that she is careful about what she cooks to keep her Type 2 diabetes mellitus, hypertension and hyperlipidaemia controlled. You were happy to note her compliance to medications (metformin $850 \mathrm{mg}$ three times daily, glipizide $10 \mathrm{mg}$ twice daily and amlodipine $10 \mathrm{mg}$ every morning). Her blood pressure was $140 / 90 \mathrm{mmHg}$, and her home blood pressure diary revealed similar readings over the past few months. Laboratory results showed a glycated haemogloblin level of $8.0 \%$, serum creatinine of $112 \mu \mathrm{mol} / \mathrm{L}$ (estimated glomerular filtration rate $48 \mathrm{~mL} / \mathrm{min} / 1.73 \mathrm{~m}^{2}$ ) and urine albumin/creatinine ratio of $40 \mathrm{mg} / \mathrm{mmol}$; four months ago, they were $7.8 \%, 106 \mu \mathrm{mol} / \mathrm{L}\left(51 \mathrm{~mL} / \mathrm{min} / 1.73 \mathrm{~m}^{2}\right)$ and $30 \mathrm{mg} / \mathrm{mmol}$ respectively. She would soon undergo panretinal photocoagulation on her right eye, but she was scared because the ophthalmologist had said that diabetes mellitus may lead to kidney failure. She asked if there was anything you could do to help her avoid needing dialysis.

\section{WHAT IS DIABETIC KIDNEY DISEASE?}

Diabetic nephropathy is traditionally defined as the presence of albuminuria and retinopathy in diabetes mellitus. More broadly, diabetic kidney disease (DKD) refers to the clinical entity of albuminuria, decreased glomerular filtration rate (GFR) or both in diabetes mellitus.

\section{HOW RELEVANT IS THIS TO MY PRACTICE?}

Approximately $25 \%-40 \%$ of all patients with diabetes mellitus develop DKD. (1) DKD is the leading cause of end-stage kidney disease (ESKD) in Singapore, with the number of patients initiated on dialysis due to DKD rising 74\% from 2009 to 2018.(2) Singapore has the world's third highest incidence of treated ESKD due to DKD, at 221 per million population. ${ }^{(3)}$ Many more patients with DKD die before they are initiated on dialysis, as DKD is strongly associated with additional cardiovascular mortality.

\section{WHY DO DIABETIC PATIENTS GET KIDNEY DISEASE?}

Diabetes mellitus causes kidney damage through complex, overlapping mechanisms. ${ }^{(4)}$ Two key pathways are chronic hyperglycaemia and renin-angiotensin system (RAS) activation.

Chronic hyperglycaemia leads to the accumulation of advanced glycation end-products, reactive oxygen species and inflammatory cytokines. This causes glomerular inflammation, structural changes, such as thickening of the glomerular basement membrane, and mesangial matrix expansion.

Hyperglycaemia increases the amount of glucose filtered at the glomerulus. Correspondingly, sodium-glucose cotransporters
(SGLT-1 and -2) are upregulated to reabsorb increased amounts of filtered glucose. This decreases sodium chloride delivery to the distal tubule, which is sensed by the macula densa and results in RAS activation. The combination of afferent arteriole vasodilation and efferent arteriole vasoconstriction increases intraglomerular pressures, causing physical stress to the glomeruli and triggering a profibrotic response.

These processes eventually lead to glomerular sclerosis, albuminuria and kidney impairment.

\section{WHAT CAN I DO IN MY PRACTICE?}

As untreated DKD progresses inexorably towards ESKD, the goal of treatment is to prevent or delay the development of ESKD. The role of the family physician is, firstly, to make a timely diagnosis of DKD through screening of individuals with diabetes mellitus and secondly, to retard the progression of DKD through glycaemic control, blood pressure control, RAS blockade, SGLT-2 inhibition and avoidance of further kidney insults. Thirdly, the family physician has an important role in health promotion and in managing comorbidities, especially cardiovascular risk factors.

\section{Screening for diabetic kidney disease}

DKD is primarily diagnosed on screening. All diabetic patients should receive annual screening for DKD, beginning five years after the diagnosis of Type 1 diabetes mellitus and at the time of diagnosis of Type 2 diabetes mellitus (as the time of disease onset is unknown). DKD is identified in a diabetic patient by the presence of persistent albuminuria and/or reduced GFR, as well as the exclusion of other causes of kidney disease.

\footnotetext{
${ }^{1}$ SingHealth Internal Medicine Residency Programme, ${ }^{2}$ SingHealth Family Medicine Residency Programme, ${ }^{3}$ Department of Renal Medicine, Singapore General Hospital, ${ }^{4}$ Department of Renal Medicine, Sengkang General Hospital, Singapore

*These two authors contributed equally as first author in this work.

Correspondence: Dr Tsang Li Ping Marianne, Resident, 681 Punggol Drive, Oasis Terraces, \#02-01, Singapore 820681. marianne.tsang@gmail.com
} 


\section{Persistent albuminuria}

The preferred proteinuria screen is a spot urinary albumin-creatinine ratio (UACR), which is more convenient than 24-hour urine protein measurement. Urine dipsticks are inadequately sensitive, inadequately specific, and non-quantitative. DKD is diagnosed if the UACR is persistently $\geq 2.5 \mathrm{mg} / \mathrm{mmol}(25 \mathrm{mg} / \mathrm{g}$ ) in males and $\geq 3.5 \mathrm{mg} / \mathrm{mmol}$ (35 mg/g) in females (Table I). Two abnormal measurements taken at least three months apart are required. A minority of patients with DKD develop reduced GFR in the absence of proteinuria.

\section{Reduced glomerular filtration rate}

GFR can be estimated based on serum creatinine levels. Among the three estimation equations - the Cockcroft-Gault, Modification of Diet in Renal Disease (MDRD) and Chronic Kidney Disease Epidemiology Collaboration (CKD-EPI) equations - we favour the CKD-EPI, which is standardised for modern creatinine assays and is most accurate for GFR $>60 \mathrm{~mL} / \mathrm{min} / 1.73 \mathrm{~m}^{2}$. Clinicians should consider the limitations of estimation equations, particularly at extremes of age and weight. A sustained reduction in GFR to below $60 \mathrm{~mL} / \mathrm{min} / 1.73 \mathrm{~m}^{2}$ for more than three months is consistent with DKD.

\section{Exclusion of other causes of kidney disease}

The majority of diabetic patients with kidney impairment have DKD, and kidney biopsy is not routine. However, it is important to consider whether kidney impairment could be due to a process other than DKD. The presence of longstanding, poorly controlled diabetes mellitus makes DKD more likely. This is not always easy to ascertain, as patients with Type 2 diabetes mellitus may have been hyperglycaemic for years before they are diagnosed. On the other hand, kidney impairment in a patient known to have excellent diabetic control for many years, or kidney impairment developing within the first five years of Type 1 diabetes mellitus, may require consideration of causes other than DKD. While the presence of diabetic retinopathy suggests longstanding hyperglycaemia and makes DKD more likely, the absence of diabetic retinopathy does not necessarily rule out DKD. ${ }^{(5,6)}$ Red flags that should prompt a referral to a nephrologist are discussed in the section 'When should I refer to a specialist?'.

\section{Retard diabetic kidney disease progression Glycaemic control (target $\sim 7.0 \%$ )}

In Type 1 diabetes mellitus, there is strong evidence that intensive glycaemic control improves kidney outcomes. The Diabetes Control and Complications Trial demonstrated that intensive glycaemic control early in the course of Type 1 diabetes mellitus (achieving median glycated haemoglobin [HbA1c] level of $7.3 \%$ vs. $9.1 \%$ in the control group) decreased the long-term incidence of reduced GFR and ESKD. ${ }^{(7)}$

Studies on Type 2 diabetes mellitus have had mixed results. There is some evidence that intensive glycaemic control (HbA1c $6.4 \%-6.9 \%$ ) may reduce the onset and progression of microalbuminuria, ${ }^{(8)}$ while a reduction in long-term incidence of ESKD was seen in only one major study (ADVANCE-ON). ${ }^{(9)}$
Table I. Categories of persistent albuminuria.

\begin{tabular}{|llll|}
\hline UACR & $\begin{array}{l}\text { Normal to mildly } \\
\text { increased }\end{array}$ & $\begin{array}{l}\text { Moderate } \\
\text { albuminuria }\end{array}$ & $\begin{array}{l}\text { Severe } \\
\text { albuminuria }\end{array}$ \\
\hline In $\mathrm{mg} / \mathrm{mmol}$ & $<2.5$ (male) & $2.5-30$ (male) & 30 \\
\cline { 2 - 3 } & $<3.5$ (female) & $3.5-30$ (female) \\
\hline In $\mathrm{mg} / \mathrm{g}$ & $<25$ (male) & $25-300$ (male) & \multicolumn{2}{|c|}{300} \\
\cline { 2 - 3 } & $<35$ (female) & $35-300$ (female) \\
\hline
\end{tabular}

UACR: urinary albumin-creatinine ratio

Major guidelines state that the HbA1c target in DKD should, in general, be about $7.0 \%$.

$\mathrm{HbA1c}$ targets must be individualised; for example, recurrent episodes of hypoglycaemia and older age would prompt the choice of a less stringent target. It is good practice to clearly document the HbA1c target chosen, so that this can be shared with other healthcare practitioners.

\section{Blood pressure control (target $<130 / 80 \mathrm{mmHg}$ )}

The optimal blood pressure (BP) target in DKD is debated. While there is clear evidence of the kidney and cardiovascular benefit of lowering systolic BP below $140 \mathrm{mmHg}$, further reductions in BP have historically been controversial, with the Kidney Disease Improving Global Outcomes guideline ${ }^{(10)}$ recommending < $130 / 80 \mathrm{mmHg}$ in albuminuric chronic kidney disease (CKD), while others (such as the Joint National Committee- 8 guideline) recommended $<140 / 90 \mathrm{mmHg}$. More recently, BP targets have been challenged by the SPRINT trial, which demonstrated the mortality benefit of a systolic BP target of $<120 \mathrm{mmHg}$ versus a target of $<140 \mathrm{mmHg}$ in non-diabetic patients. ${ }^{(11)}$

Most CKD patients will require more than one, and often three, antihypertensive agents to achieve the target BP. RAS blockade should be the first antihypertensive drug of choice.

\section{Renin-angiotensin system blockade}

Angiotensin-converting enzyme inhibitors (ACE-Is) and angiotensin receptor blockers (ARBs) have a central role in reversing glomerular hypertension, mitigating albuminuria and slowing the decline in kidney function in DKD, over and above BP targets achieved. The presence of hypertension or albuminuria in DKD is an indication for use of ACE-Is or ARBs (Table II). Typical doses of ACE-Is and ARBs are shown in Table III. In practice, optimal use of ACE-Is and ARBs in DKD is not always achieved. Important points are as follows:

- Choose any ACE-I or ARB, start low, and titrate upwards to the maximum tolerated dose. The various ACE-Is and ARBs are considered equally efficacious. If the ACE-I causes cough, switch to an ARB. Optimise the dose by gradual uptitration until (a) the maximum dose is attained, (b) blood pressure is on target and normoalbuminuria is achieved, or (c) further increases are not tolerated (e.g. symptoms of postural giddiness or blood pressure $<120 / 80 \mathrm{mmHg}$ without any other antihypertensive drugs).

- $\quad$ Recheck serum potassium and creatinine two weeks after starting ACE-I or ARB or after a dose increase. 
This is sometimes neglected. ACE-Is and ARBs reduce intraglomerular hypertension via efferent arteriole vasodilation, which slightly reduces GFR and therefore leads to a small rise in creatinine. A rise of $20 \%-30 \%$ is expected. If creatinine rises $>30 \%$ or serum potassium rises $>5.5 \mathrm{mmol}$, stop the ACE-I/ARB and refer to a nephrologist for workup of possible renal artery stenosis.

- If hyperkalaemia limits ACE-I/ARB dosing, reduce diet potassium before stopping the drug. Hyperkalaemia is often feared and many clinicians discontinue the ACE-I/ $A R B$ in the face of hyperkalaemia, denying patients the renoprotective effect of RAS blockade. The first response to hyperkalaemia should be to enforce a low-potassium diet. While temporarily suspending or reducing the dose of ACE-I/ARB may be necessary, every effort should be made to restart it once potassium is controlled. Adding a thiazide or loop diuretic may also be helpful.

- Reduced GFR is not a contraindication. Absolute contraindications include pregnancy and angio-oedema due to ACE-I/ARB. Some clinicians avoid RAS blockade in patients with reduced GFR. However, patients with reduced GFR benefit most from RAS blockade, which can retard further falls in GFR. The ACE-I/ARB only needs to be stopped in patients who are approaching dialysis dependence.

- Do not combine ACE-Is and ARBs. Large trials have told us that this is associated with more adverse events of hyperkalaemia and kidney injury without additional clinical benefit. ${ }^{(12,13)}$

\section{SGLT-2 inhibition}

The SGLT-2 inhibitor (dapagliflozin, canagliflozin and empagliflozin) is a promising new drug class that has been shown to retard the progression of diabetic nephropathy. SGLT-2 inhibitors inhibit proximal tubule reabsorption of glucose and sodium, promoting glycosuria and natriuresis, which lowers blood glucose and BP. The increase in sodium delivery to the distal tubules inhibits tubuloglomerular feedback, reducing glomerular hypertension and creating a renoprotective effect. A meta-analysis of the three major SGLT-2 outcome trials (DECLARE-TIMI, EMPA-REG outcome and (REDENCE) showed that SGLT-2 inhibitors reduced major adverse cardiovascular events (myocardial infarction, stroke or cardiovascular death) and slowed the progression of kidney disease. ${ }^{(14)}$

Guidelines for the use of SGLT-2 inhibitors are evolving. In the CREDENCE trial, canagliflozin was given to DKD patients who had albuminuria (UACR > $300 \mathrm{mg} / \mathrm{g}$ ) and impaired estimated GFR (eGFR) of $30-90 \mathrm{~mL} / \mathrm{min} / 1.73 \mathrm{~m}^{2}$, and were already on ACE-I/ ARB treatment. ${ }^{(15)}$ The EMPA-REG trial also included DKD patients with normal GFR $\geq 90 \mathrm{~mL} / \mathrm{min} / 1.73 \mathrm{~m}^{2}$ (21\% of participants) or no albuminuria (60\% of participants). ${ }^{(16)}$ Both trials showed kidney benefit from SGLT-2 inhibition. SGLT-2 inhibitors can be used in DKD patients who have persistent albuminuria in spite of optimised ACE-I/ARB treatment, or who require a second (or third) oral hypoglycaemic agent for suboptimal glycaemic control despite treatment with metformin and lifestyle and dietary modifications. They are not considered first-line therapy at present. Important contraindications and cautions to the use of SGLT-2 inhibitors are:

- $\quad$ CKD Stage 3B or worse: SGLT-2 inhibitors should not routinely be started when eGFR $<45 \mathrm{~mL} / \mathrm{min} / 1.73 \mathrm{~m}^{2}$, and should be stopped if eGFR $<30 \mathrm{~mL} / \mathrm{min} / 1.73 \mathrm{~m}^{2}$. (With the CREDENCE trial, it is possible that the eGFR for starting SGLT-2 inhibitor may be lowered to $30 \mathrm{~mL} / \mathrm{min} / 1.73 \mathrm{~m}^{2}$.)

- $\quad$ Previous diabetic ketoacidosis (DKA): euglycaemic DKA has been reported in patients taking SGLT-2 inhibitors, but the absence of hyperglycaemia delays recognition of DKA.

- $\quad$ Type 1 diabetes mellitus: Key SGLT-2 trials were performed in Type 2 diabetes mellitus patients, and patients with Type 1 diabetes mellitus are at increased risk of DKA.

- Frequent urinary tract infections: increased rates of genitourinary infections have been reported with SGLT-2 inhibitors.

- $\quad$ Patients with history of lower limb amputation or at risk of lower limb amputation and patients with peripheral vascular disease or lower limb ulcers: SGLT-2 inhibitors, in particular canagliflozin, are associated with an increased risk of amputation.

With SGLT-2 inhibitors, start low and titrate upwards. In patients with well-controlled diabetes mellitus on insulin, it may be necessary to reduce the insulin dose by $5 \%-10 \%$ to avoid hypoglycaemia. Avoid excessive reductions in insulin dose, as this increases the risk of euglycaemic DKA. As SGLT-2 inhibitors have a diuretic effect, consider decreasing the dose of existing diuretics in patients who are clinically euvolaemic, and reassessing fluid status in 1-2 weeks. Counsel patients on the symptoms of ketoacidosis and risk of urinary tract infections.

Table II. Use of angiotensin inhibition in diabetes mellitus subgroups.

\begin{tabular}{|c|c|c|}
\hline Subgroup & Recommendation & $\begin{array}{l}\text { Landmark } \\
\text { studies }\end{array}$ \\
\hline $\begin{array}{l}\text { Reduced eGFR } \\
<60 \mathrm{~mL} / \mathrm{min} / 1.73 \mathrm{~m}^{2}\end{array}$ & \multirow{3}{*}{$\begin{array}{l}\text { ACE-I/ARB is of } \\
\text { definite benefit } \\
\text { in reducing } \\
\text { albuminuria and } \\
\text { slowing GFR } \\
\text { decline. }\end{array}$} & $\begin{array}{l}\text { Captopril trial } \\
\text { (1993) }\end{array}$ \\
\hline $\begin{array}{l}\text { Preserved GFR and } \\
\text { macroalbuminuria (UACR } \\
\geq 30 \mathrm{mg} / \mathrm{mmol} \text { ) }\end{array}$ & & $\begin{array}{l}\text { RENAAL (2001) } \\
\text { IDNT (2001) }\end{array}$ \\
\hline $\begin{array}{l}\text { Preserved GFR and } \\
\text { microalbuminuria (UACR } \\
2.5-30 \mathrm{mg} / \mathrm{mmol} \text { [male] or } \\
3.5-30 \mathrm{mg} / \mathrm{mmol} \text { [female]) }\end{array}$ & & $\begin{array}{l}\text { IRMA-2 (2001) } \\
\text { DETAIL (2004) } \\
\text { INNOVATION } \\
(2007)\end{array}$ \\
\hline $\begin{array}{l}\text { Preserved GFR, no } \\
\text { albuminuria, and } \\
\text { hypertension (systolic BP } \\
>130 \mathrm{mmHg} \text { ) }\end{array}$ & $\begin{array}{l}\text { ACE-I/ARB delays } \\
\text { the onset of } \\
\text { microalbuminuria. }\end{array}$ & $\begin{array}{l}\text { BENEDICT (2004) } \\
\text { ROADMAP } \\
(2011)\end{array}$ \\
\hline $\begin{array}{l}\text { Preserved GFR, no } \\
\text { albuminuria, and } \\
\text { normal BP }\end{array}$ & $\begin{array}{l}\text { No evidence } \\
\text { of benefit with } \\
\text { ACE-I/ARB. }\end{array}$ & $\begin{array}{l}\text { DIRECT (2009) } \\
\text { RASS (2009) }\end{array}$ \\
\hline
\end{tabular}

ACE-I: angiotensin-converting enzyme inhibitor; ARB: angiotensin receptor blocker; BP: blood pressure; eGFR: estimated glomerular filtration rate; GFR: glomerular filtration rate; UACR: urinary albumin-creatinine ratio 
Table III. Recommended doses of common ACE-Is, ARBs and SGLT-2 inhibitors.

\begin{tabular}{|c|c|c|c|c|}
\hline Drug & Starting dose & Maximum dose & Cost* & Remark \\
\hline \multicolumn{5}{|l|}{ ACE-I } \\
\hline Enalapril & $2.5-5 \mathrm{mg}$ OD & $40 \mathrm{mg}$ OD & $\$$ & \multirow{4}{*}{$\begin{array}{l}\text { Can also be given as a divided daily dose (e.g. enalapril } 20 \mathrm{mg} \mathrm{BD} \\
\text { instead of } 40 \mathrm{mg} \text { OD). This is particularly helpful if there is nocturnal } \\
\text { hypertension. }\end{array}$} \\
\hline Lisinopril & $2.5-5 \mathrm{mg}$ OD & $40 \mathrm{mg}$ OD & $\$$ & \\
\hline Perindopril & $2-4 \mathrm{mg}$ OD & $8-16 \mathrm{mg}$ OD & $\$ \$$ & \\
\hline Ramipril & $2.5 \mathrm{mg}$ OD & $20 \mathrm{mg}$ OD & $\$ \$$ & \\
\hline Captopril & $6.25 \mathrm{mg}$ TDS & $50 \mathrm{mg}$ TDS & $\$$ & Not favoured due to TDS dosing. \\
\hline \multicolumn{5}{|l|}{ ARB } \\
\hline Losartan & $25-50 \mathrm{mg}$ OD & $100 \mathrm{mg}$ OD & $\$ \$$ & \multirow{6}{*}{$\begin{array}{l}\text { Older ARBs (e.g. losartan) tend to have a weaker BP lowering effect, } \\
\text { while newer ARBs (e.g. telmisartan) are stronger antihypertensives. } \\
\text { Therefore, choose losartan for patients with proteinuria and mildly } \\
\text { elevated BP, and a newer ARB in patients who require stronger BP } \\
\text { control. }\end{array}$} \\
\hline Valsartan & $20-40$ mg BD & 160 mg BD & $\$ \$$ & \\
\hline Telmisartan & $20 \mathrm{mg}$ OD & 80 mg OD & $\$ \$$ & \\
\hline Candesartan & $4-8 \mathrm{mg} \mathrm{OD}$ & $32 \mathrm{mg}$ OD & $\$ \$ \$^{+}$ & \\
\hline Irbesartan & $75-150 \mathrm{mg}$ OD & $300 \mathrm{mg}$ OD & $\$ \$$ & \\
\hline Olmesartan & $20 \mathrm{mg}$ OD & $40 \mathrm{mg}$ OD & $\$ \$ \$$ & \\
\hline \multicolumn{5}{|l|}{ SGLT-2 inhibitor } \\
\hline Empagliflozin & $5-10 \mathrm{mg}$ OD & $25 \mathrm{mg}$ OD & $\$ \$ \$^{\dagger}$ & \multirow{2}{*}{$\begin{array}{l}\text { In kidney impairment } \\
\text { - eGFR } \geq 45 \mathrm{~mL} / \mathrm{min} / 1.73 \mathrm{~m}^{2} \text { : full dose } \\
\text { - eGFR } 30-45 \mathrm{~mL} / \mathrm{min} / 1.73 \mathrm{~m}^{2} \text { : initiation not advised } \\
\text { - eGFR }<30 \mathrm{~mL} / \mathrm{min} / 1.73 \mathrm{~m}^{2} \text { : contraindicated }\end{array}$} \\
\hline Dapagliflozin & 5-10 mg OD & $10 \mathrm{mg}$ OD & $\$ \$ \$^{+}$ & \\
\hline Canagliflozin & $100 \mathrm{mg}$ OD & $300 \mathrm{mg}$ OD & $N / A^{\ddagger}$ & $\begin{array}{l}\text { In kidney impairment } \\
\cdot \text { eGFR } \geq 60 \mathrm{~mL} / \mathrm{min} / 1.73 \mathrm{~m}^{2} \text { : full dose } \\
\cdot \text { e } \mathrm{eGR} 45-60 \mathrm{~mL} / \mathrm{min} / 1.73 \mathrm{~m}^{2}: 100 \mathrm{mg} \text { OD } \\
\cdot \text { e } \mathrm{GFR} 30-40 \mathrm{~mL} / \mathrm{min} / 1.73 \mathrm{~m}^{2} \text { with urinary albumin }>300 \mathrm{mg} / \text { day: } 100 \\
\mathrm{mg} \mathrm{OD} \\
\cdot \text { e } \mathrm{eGRR}<30 \mathrm{~mL} / \mathrm{min} / 1.73 \mathrm{~m}^{2} \text { : contraindicated }\end{array}$ \\
\hline
\end{tabular}

*Cost estimate in Singapore public healthcare institutions. $†$ Needy patients may qualify for medication assistance fund. ¥Not in polyclinic formulary at time of writing. \$: standard drug list 1 (fixed weekly cost regardless of dose); \$: standard drug list 2 (50\% subsidy); \$\$: non-standard drugs (not subsidised); ACE-I: angiotensinconverting enzyme inhibitor; ARB: angiotensin receptor blocker; BD: twice daily; BP: blood pressure; eGFR: estimated glomerular filtration rate; OD: once a day; SGLT-2: sodium glucose cotransporter-2; TDS: three times daily

\section{Avoidance of further kidney insult}

Episodes of acute kidney injury accelerate the progression of CKD and should be avoided. ${ }^{(17)}$ A simple checklist could include:

- Is my patient's drug list appropriate for his/her kidney function? Nonsteroidal anti-inflammatory drugs predictably cause acute kidney injury in patients with DKD.

- $\quad$ Are my patient's drug doses appropriate for his/her kidney function? As estimated glomerular filtration rate (eGFR) falls, dose reductions or stopping drugs (e.g. metformin) may be necessary.

- Is my patient taking any potentially nephrotoxic traditional medicine or supplements?

- Is my patient becoming dehydrated due to diuretics, or SGLT-2 inhibitors?

\section{Health promotion and management of comorbidities}

Cardiovascular disease is the main cause of death in DKD. The physician should pay attention to the usual cardiovascular riskreduction measures, including lipid-lowering and antiplatelet therapy if indicated. Non-pharmacological measures are equally important and must include:

- Patient education on the course of DKD, common symptoms to expect and measures to retard the progression of DKD
- Dietary advice, particularly on salt, calorie and glucose intake appropriate to comorbidities

- $\quad$ Advice on avoidance of nephrotoxic drugs and supplements

- Vaccinations, including influenza and pneumococcal vaccines

- Weight management through exercise and dietary measures

- Smoking cessation

WHEN SHOULD I REFER TO A SPECIALIST?

Patients should be referred to a nephrologist for further workup if non-diabetic kidney disease (NDKD) is suspected, or if they are approaching ESKD. Box 1 shows the red flags that are suggestive of NDKD, which should prompt referral for further workup, including kidney biopsy.

\section{Patients approaching end-stage kidney disease}

Patients with DKD will face complications or symptoms of kidney failure at eGFR $<30 \mathrm{~mL} / \mathrm{min} / 1.73 \mathrm{~m}^{2}$. Most patients will require renal replacement therapy at eGFR $<10 \mathrm{~mL} / \mathrm{min} / 1.73 \mathrm{~m}^{2}$. Early referral for elective initiation of renal replacement therapy improves mortality. ${ }^{(18)}$ Preparation for renal replacement therapy typically takes about 12 months, including shared decision-making on the modality of renal replacement therapy, as well as access creation. Therefore, consider a nephrology referral (a) when GFR falls to approximately $30 \mathrm{~mL} / \mathrm{min} / 1.73 \mathrm{~m}^{2}$; (b) at higher GFRs if the decline is rapid (> $5 \mathrm{~mL} / \mathrm{min} / 1.73 \mathrm{~m}^{2}$ per year); or (c) at any GFR 
if there are complications that cannot be managed in primary care (e.g. severe anaemia requiring erythropoiesis-stimulating agents, marked hyperphosphataemia or chronic metabolic acidosis).

In the absence of a pressing indication for urgent renal replacement therapy, many patients delay or decline nephrology referral. The family physician should explain that preparing for renal replacement therapy takes time and that planning ahead is preferable to being in a life-threatening situation requiring urgent dialysis. It is often necessary to pace the process with the patient and revisit this conversation at multiple visits. Apart from discussing dialysis planning, it is also important to educate the patient about red flag symptoms that should prompt an immediate emergency department consultation, as well as the importance of fluid restriction and a low-potassium diet.

\section{HOW CAN I MANAGE COMPLICATIONS OF DIABETIC KIDNEY DISEASE?}

Complications of DKD that family physicians commonly encounter include fluid overload and mild to moderate anaemia. The family physician may also need to manage symptoms of ESKD in patients who decline dialysis.

\section{Fluid overload}

Patients with DKD rarely face overt fluid overload until eGFR falls below $15 \mathrm{~mL} / \mathrm{min} / 1.73 \mathrm{~m}^{2}$, in the absence of concomitant heart failure or another cause of fluid overload. The first step in management is to restrict salt (sodium $<2 \mathrm{~g} /$ day) and fluid intake. A loop diuretic such as furosemide is usually effective in treating fluid overload. Monitor electrolytes (particularly potassium) with the use of diuretics but avoid routine prescription of supplemental potassium in patients with reduced GFR and baseline serum potassium $\geq 5.0 \mathrm{mmol} / \mathrm{L}$. Thiazide diuretics are ineffective below a GFR of $30 \mathrm{~mL} / \mathrm{min} / 1.73 \mathrm{~m}^{2}$ and should be replaced by loop diuretics.

\section{Anaemia}

As GFR falls below $30 \mathrm{~mL} / \mathrm{min} / 1.73 \mathrm{~m}^{2}$, declining erythropoietin production by the kidneys begins to cause a normocytic, normochromic anaemia. Before attributing anaemia to DKD, exclude other causes by checking iron studies, vitamin B12 and folate, and consider a referral for endoscopy in the presence of iron deficiency anaemia.

In treating anaemia of kidney disease, the first step is to ensure that the patient is iron replete. Initiate iron supplements if there is anaemia with transferrin saturation $\leq 30 \%$ and/or ferritin $\leq 500 \mathrm{ng} / \mathrm{mL}$. If anaemia persists after correction of iron deficiency, an erythropoiesis-stimulating agent is indicated, aiming for a haemoglobin target of 10-11.5 g/dL. Erythropoiesisstimulating agents are generally unavailable in the primary care setting and will require specialist referral.

Box 1. Red flags for suspected non-diabetic kidney disease:
- Rapid progression of kidney disease (estimated glomerular
filtration rate [eGFR] decline $>5 \mathrm{~mL} / \mathrm{min} / 1.73 \mathrm{~m}^{2}$ per year). This is
an arbitrary threshold. While the rate of eGFR decline in diabetic
kidney disease can at times exceed $5 \mathrm{~mL} / \mathrm{min} / 1.73 \mathrm{~m}^{2}$, it may be an
indication to investigate for causes of non-diabetic kidney disease.
- Persistent haematuria or active urinary sediment (red/white cell casts).
- Frank nephrotic syndrome or nephritic syndrome.
- Signs or symptoms of systemic disease such as autoimmune
causes of kidney disease, e.g. systemic lupus erythematosus.
- Anaemia and hypercalcaemia out of proportion to kidney
impairment - consider multiple myeloma.
- Resistant hypertension or eGFR decline $>30 \%$ after starting
angiotensin inhibition - consider renal artery stenosis.

\section{Table IV. Palliative management of common symptoms* in end-stage kidney disease.}

\begin{tabular}{|c|c|c|}
\hline Symptom & Mechanism & First-line treatment \\
\hline \multirow[t]{7}{*}{ Dyspnoea } & \multirow[t]{2}{*}{ Fluid overload } & - Fluid restriction \\
\hline & & - Diuresis: may require high doses of furosemide \\
\hline & Anaemia & - Erythropoiesis-stimulating agents if within goal of care \\
\hline & \multirow[t]{2}{*}{ Anxiety } & - Non-pharmacological, e.g. deep breathing exercises \\
\hline & & - Low-dose short-acting benzodiazapines. \\
\hline & \multirow{2}{*}{$\begin{array}{l}\text { Regardless of } \\
\text { mechanism }\end{array}$} & - Non-pharmacological, e.g. hand-held fan blowing on face \\
\hline & & - Opioids (fentanyl is the opioid of choice; morphine and tramadol can accumulate in kidney disease) \\
\hline \multirow[t]{3}{*}{ Nausea and vomiting } & Uraemia & - Haloperidol (more effective than metoclopramide). Start at 0.5 mg orally every 6-8 hourly PRN \\
\hline & Gastroparesis & - Domperidone or metoclopramide \\
\hline & Constipation & - Bowel clearance with regular laxatives (avoid fleet enema due to high phosphate load) \\
\hline \multirow[t]{5}{*}{ Pruritus } & \multirow{5}{*}{$\begin{array}{l}\text { Mechanism is } \\
\text { poorly understood }\end{array}$} & - Non-pharmacological: tepid showers, light clothing \\
\hline & & - Antihistamines do not reduce uraemic pruritus, but sedating antihistamines may help with sleep \\
\hline & & - Gabapentin (e.g. 50-100 mg ON): with caution and close monitoring as it can accumulate and \\
\hline & & cause drowsiness. \\
\hline & & - Mirtazapine may reduce central sensitisation to itch. \\
\hline
\end{tabular}

*Besides the symptoms listed, end-stage kidney disease patients also experience general fatigue or malaise, musculoskeletal aches and pains, nonspecific dizziness, and sexual dysfunction. There is little we can do to alleviate these symptoms, and as physicians, we have a tendency not to address them. However, these symptoms can have a significant impact on quality of life and are often the reason patients seek complementary and alternative medicine. Simply acknowledging the presence of these symptoms and educating patients that these symptoms come together with their'weak kidney' (experienced by many others with the same condition), can be helpful in reducing frustration and reaching acceptance. ON: every night; PRN: whenever necessary 


\section{Palliative management of ESKD}

Some patients with ESKD decline renal replacement therapy due to advanced age, personal values and preferences, or social constraints. Other patients are unlikely to benefit from renal replacement therapy due to severe life-limiting illnesses or poor premorbid quality of life. Many symptoms of ESKD can be managed in primary care (Table IV). ${ }^{(19,20)}$ Patients with more complex symptoms or who fail to respond to first-line measures may benefit from specialist palliative care or home hospice referral. Prognostication of ESKD patients who have never undergone renal replacement therapy is challenging, with median survival ranging from six months to two years. ${ }^{(20)}$ In contrast, for ESKD patients on longstanding renal replacement therapy in whom dialysis support is withdrawn, death can be predicted with relative certainty in less than two weeks.

\section{TAKE HOME MESSAGES}

1. All diabetic patients should be screened for DKD, defined by the presence of persistent proteinuria (UACR $\geq 2.5 \mathrm{mg} / \mathrm{mmol}$ [25 mg/g] in males or $\geq 3.5 \mathrm{mg} / \mathrm{mmol}$ [35 mg/g] in females) and/or reduced GFR.

2. The key objective in the management of DKD is to retard the decline of GFR. This is achieved by optimising glycaemic control (target $\mathrm{HbA} 1 \mathrm{c} 7.0 \%$ ), BP control (target $\mathrm{BP}<130 / 80 \mathrm{mmHg}$ in albuminuric DKD) and RAS blockade. SGLT-2 inhibitors are beneficial, particularly in patients with persistent albuminuria, but are avoided if eGFR $<30 \mathrm{~mL} / \mathrm{min} / 1.73 \mathrm{~m}^{2}$.

3. Consider referral to a nephrologist when eGFR $<30 \mathrm{~mL} / \mathrm{min} / 1.73 \mathrm{~m}^{2}$, in patients with rapid decline of GFR (> $5 \mathrm{~mL} / \mathrm{min} / 1.73 \mathrm{~m}^{2}$ per year), or when NDKD is suspected.

You diagnose diabetic kidney disease in Mdm Chee after checking for red flags that were inconsistent with the diagnosis. You started her on linagliptin $5 \mathrm{mg}$ and losartan $25 \mathrm{mg}$ every morning, with a planned review in two weeks to recheck her renal panel and uptitrate losartan. You explained the diagnosis of diabetic kidney disease to $\mathrm{Mdm}$ Chee and counselled her on optimal glycaemic and blood pressure control, recommending a low-salt, diabetic diet. Three months later, $\mathrm{Mdm}$ Chee's blood pressure was 128/76 mmHg and her urinary albumin-creatinine ratio had decreased to $10 \mathrm{mg} / \mathrm{mmol}$ on losartan $100 \mathrm{mg}$ every morning. Her glycated haemoglobin level was $7.1 \%$, and her creatinine level was stable at $115 \mu \mathrm{mol} / \mathrm{L}$.
4. Preparation for renal replacement therapy can take up to 12 months, and early nephrology referral is associated with better outcomes.

5. Many complications of DKD can be managed in primary care.

\section{REFERENCES}

1. Afkarian $M$, Zelnick $L$, Hall $Y$, et al. Clinical manifestations of kidney disease among us adults with diabetes, 1988-2014. JAMA 2016; 316:602-10

2. National Registry of Diseases Office, Health Promotion Board, Singapore. Singapore Renal Registry Annual Report 2018. Available at: https://www. nrdo.gov.sg/docs/librariesprovider3/default-document-library/singaporerenal-registry-annual-report-2018.pdf?sfvrsn=de5a657f_0. Accessed July 23, 2020.

3. Saran R, Robinson B, Abbott KC, et al. United States Renal Data System 2018 annual data report: epidemiology of kidney disease in the United States. Am J Kidney Dis 2019; 73(3 Suppl 1):A7-A8.

4. Alicic RZ, Rooney MT, Tuttle KR. Diabetic kidney disease: challenges, progress, and possibilities. Clin J Am Soc Nephrol 2017; 12:2032-45.

5. Wolf G, Müller N, Mandecka A, Müller UA. Association of diabetic retinopathy and renal function in patients with Types 1 and 2 diabetes mellitus. Clin Nephrol 2007; 68:81-6.

6. Penno G, Solini A, Zoppini G, et al. Rate and determinants of association between advanced retinopathy and chronic kidney disease in patients with type 2 diabetes: the Renal Insufficiency And Cardiovascular Events (RIACE) Italian multicenter study. Diabetes Care 2012; 35:2317-23.

7. The Writing Team for the Diabetes Control and Complications Trial/ Epidemiology of Diabetes Interventions and Complications Research Group. Effect of intensive therapy on the microvascular complications of type 1 diabetes mellitus. JAMA 2002; 287:2563-9.

8. Ruospo M, Saglimbene VM, Palmer SC, et al. Glucose targets for preventing diabetic kidney disease and its progression. Cochrane Database Syst Rev 2017; 6:CD010137

9. Zoungas $\mathrm{S}$, Chalmers J, Neal B, et al. Follow-up of blood-pressure lowering and glucose control in type 2 diabetes. N Engl J Med 2014; 371:1392-406.

10. Kidney Disease: Improving Global Outcomes (KDIGO) CKD Work Group. KDIGO 2012 Clinical Practice Guideline for the Evaluation and Management of Chronic Kidney Disease. Kidney Int Suppl 2013; 3: 1-150.

11. The SPRINT Research Group, Wright JT Jr, Williamson JD, et al. A randomized trial of intensive versus standard blood-pressure control. N Engl J Med 2015; 373:2103-16.

12. Mann JF, Schmieder RE, McQueen M, et al. Renal outcomes with telmisartan, ramipril, or both, in people at high vascular risk (the ONTARGET study): a multicentre, randomised, double-blind, controlled trial. Lancet 2008; 372:547-53.

13. Fried LF, Emanuele $\mathrm{N}$, Zhang $\mathrm{JH}$, et al. Combined angiotensin inhibition for the treatment of diabetic nephropathy. N Engl J Med 2013; 369:1892-903.

14. Zelniker TA, Wiviott SD, Raz I, et al. SGLT2 inhibitors for primary and secondary prevention of cardiovascular and renal outcomes in type 2 diabetes: a systematic review and meta-analysis of cardiovascular outcome trials. Lancet 2019; 393:31-9.

15. Perkovic V, Jardine MJ, Neal B, et al. Canagliflozin and renal outcomes in type 2 diabetes and nephropathy. N Engl J Med 2019; 380:2295-306.

16. Zinman B, Wanner C, Lachin JM, et al. Empagliflozin, cardiovascular outcomes, and mortality in type 2 diabetes. N Engl J Med 2015; 373:2117-28.

17. Chawla LS, Eggers PW, Star RA, Kimmel PL. Acute kidney injury and chronic kidney disease as interconnected syndromes. N Engl J Med 2014; 371:58-66.

18. Chan MR, Dall AT, Fletcher KE, Lu N, Trivedi H. Outcomes in patients with chronic kidney disease referred late to nephrologists: a meta-analysis. Am J Med 2007; 120:1063-70.

19. Douglas CA. Palliative care for patients with advance chronic kidney disease. J R Coll Physicians Edinb 2014; 44:224-31.

20. Murtagh FEM. Palliative Care in Kidney Disease. In: Macleod RD, Van den Block L, eds. Textbook of Palliative Care. Switzerland: Springer International Publishing 2019: 1153. 


\section{SINGAPORE MEDICAL COUNCIL CATEGORY 3B CME PROGRAMME} (Code SMJ 202008A)

1. Diabetic kidney disease (DKD) is the leading cause of end-stage kidney disease in Singapore.

2. Key pathways in the pathogenesis of DKD include chronic hyperglycaemia and renin-angiotensin system activation.

3. All patients with Type 2 diabetes mellitus should undergo regular screening for albuminuria.

4. Urine dipsticks are appropriate for albuminuria screening in diabetic patients.

5. A normal serum creatinine level excludes the possibility of DKD.

6. A 50-year-old man who is newly diagnosed with Type 2 diabetes mellitus and moderate albuminuria is unlikely to have DKD, as the pathogenesis of DKD requires the presence of longstanding diabetes mellitus.

7. In patients with DKD and hypertension, the first antihypertensive agent of choice is an angiotensin-converting enzyme inhibitor (ACE-I) or angiotensin receptor blocker (ARB).

8. A female patient with Type 2 diabetes mellitus, a urinary albumin-creatinine ratio of $50 \mathrm{mg} / \mathrm{mmol}$ and a blood pressure of 124/80 mmHg will benefit from an ACE-I or ARB.

9. Serum potassium and creatinine should be checked two weeks after initiation of an ACE-I or ARB.

10. ACE-I or ARB is contraindicated in a patient with estimated glomerular filtration rate (eGFR) $<45 \mathrm{~mL} / \mathrm{min} / 1.73 \mathrm{~m}^{2}$.

11. A patient with Type 2 diabetes mellitus and persistent albuminuria despite maximal doses of ACE-I will benefit from the addition of ARB.

12. A patient with Type 1 diabetes mellitus who has persistent albuminuria despite maximal doses of losartan and a glycated haemoglobin level of $8.0 \%$ while on metformin and glipizide may benefit from sodiumglucose cotransporter 2 (SGLT-2) inhibition.

13. SGLT-2 inhibitors should not be started in patients who have Type 1 diabetes mellitus, eGFR $<45 \mathrm{~mL} / \mathrm{min} / 1.73 \mathrm{~m}^{2}$, a history of diabetic ketoacidosis, frequent urinary tract infections or the risk of lower limb amputations.

14. Non-pharmacologic aspects of DKD management include a low-salt, low-potassium diet, avoidance of nephrotoxic drugs and supplements, smoking cessation, vaccinations and weight management.

15. In DKD patients, it is common for the glomerular filtration rate (GFR) to decline at a rate of $10 \mathrm{~mL} / \mathrm{min} / 1.73 \mathrm{~m}^{2}$ per year.

16. A 45-year-old woman with established Type 2 diabetes mellitus and albuminuria is found to have persistent haematuria, inflammatory joint pain, leucopenia and thrombocytopenia. She should be referred to a specialist for further workup.

17. Patients with DKD who are asymptomatic should be referred for initiation of renal replacement therapy only when eGFR falls to $15 \mathrm{~mL} / \mathrm{min} / 1.73 \mathrm{~m}^{2}$.

18. In a patient with GFR $<30 \mathrm{~mL} / \mathrm{min} / 1.73 \mathrm{~m}^{2}$, thiazide diuretics should be replaced by loop diuretics.

19. Iron supplementation has little role in the treatment of anaemia in a patient with DKD.

20. Fleet enema should be avoided in patients with advanced DKD.

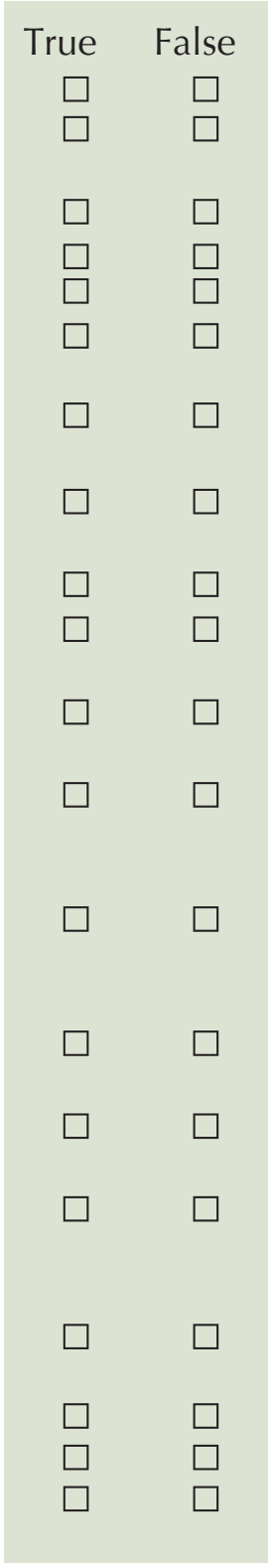

\section{Doctor's particulars:}

Name in full:

MCR no.:

Specialty:

Email:

\section{SUBMISSION INSTRUCTIONS:}

Visit the SMJ website: http://www.smj.org.sg/current-issue and select the appropriate quiz. You will be redirected to the SMA login page.

For SMA member: (1) Log in with your username and password (if you do not know your password, please click on 'Forgot your password?'). (2) Select your answers for each quiz and click 'Submit'.

For non-SMA member: (1) Create an SMJ CME account, or log in with your SMJ CME username and password (for returning users). (2) Make payment of SGD 21.40 (inclusive of $7 \%$ GST) via PayPal to access this month's quizzes. (3) Select your answers for each quiz and click 'Submit'.

RESULTS:

(1) Answers will be published online in the SMJ October 2020 issue. (2) The MCR numbers of successful candidates will be posted online at the SMJ website by 9 October 2020. (3) Passing mark is $60 \%$. No mark will be deducted for incorrect answers. (4) The SMJ editorial office will submit the list of successful candidates to the Singapore Medical Council. (5) One CME point is awarded for successful candidates. (6) SMC credits CME points according to the month of publication of the CME article (i.e. points awarded for a quiz published in the August 2020 issue will be credited for the month of August 2020, even if the deadline is in October 2020).

Deadline for submission (August 2020 SMJ 3B CME programme): 12 noon, 2 October 2020 